\title{
Dados de altimetria por satélite na caracterização morfoestrutural da plataforma continental do Rio Grande do Sul
}

Gilberto Gagg ; ${ }^{1}$ Iran Carlos Stalliviere Corrêa ${ }^{1}$; Sérgio Florêncio de Souza ${ }^{1}$.

${ }^{1}$ IGEO / Instituto de Geociências - UFRGS - Universidade Federal do Rio Grande do Sul

Copyright 2014, SBGf - Sociedade Brasileira de Geofísica

Este texto foi preparado para a apresentação no VI Simpósio Brasileiro de Geofísica, Porto Alegre, 14 a 16 de outubro de 2014. Seu conteúdo foi revisado pelo Comitê Técnico do VI SimBGf, mas não necessariamente representa a opinião da SBGf ou de seus associados. É proibida a reprodução total ou parcial deste material para propósitos comerciais sem prévia autorização da SBG.

\section{Abstract}

The characterization of the morphostructural organization of the continental shelf of Rio Grande do Sul may be done by cartographic analysis technics. The use of satellite altimetry data and computational resources, enables the bathymetric analysis of the continental shelf, pursuing the morphological configuration of the region and to understand the processes of their development and training.

\section{Introdução}

Estudos específicos realizados em regiões costeiras e plataforma continental adjacente objetivam entender quais foram suas origens, como se desenvolveu sua evolução, suas características específicas etc. Numa abordagem geológica, estes estudos implicam em identificar e conhecer todas as variáveis envolvidas desde o seu condicionamento pretérito (evolução costeira) até o atual (morfodinâmica costeira), o que envolve a investigação de interações continenteoceano e interferências da biosfera no ambiente (FONSECA, 2006). Para tal recorrem às informações geomorfológicas, oceanográficas, geológicas, geofísicas, entre outras.

O uso de dados batimétricos atualizados e de grande resolução espacial obtidos a partir de cartas batimétricas, e também dados de altimetria por satélites, conduzem à obtenção da configuração morfológica de uma região. As medições por satélites têm cobertura global, com o recobrimento homogêneo de grandes áreas oceânicas com alta resolução espacial e temporal, num curto período de tempo

No caso em questão, foi feita uma modelagem e uma análise morfoestrutural baseada num estudo cartográfico do comportamento da batimetria, através da comparação do modelo real batimétrico, e de um modelo teórico.

\section{Área de Estudo}

A área de estudo situa-se na Bacia de Pelotas, na plataforma continental do estado do Rio Grande do Sul, entre as latitudes de $29^{\circ} 00^{\prime} \mathrm{S}$ e $34^{\circ} 00^{\prime} \mathrm{S}$ e longitudes $49^{\circ} 00^{\prime} \mathrm{O}$ e $52^{\circ} 45^{\prime} \mathrm{O}$, sendo o polígono específico de estudo limitado pela isóbata $-130 \mathrm{~m}$. A plataforma continental nesta região apresenta relevo suave, com largura média de $125 \mathrm{~km}$, baixa declividade, sendo que os contornos batimétricos geralmente acompanham a morfologia da costa. Em Torres, a plataforma é larga, estreitando-se até Mostardas, voltando a apresentar-se mais ampla em direção ao Chuí.
A figura 1 apresenta o estado do Rio Grande do Sul e plataforma continental adjacente. Estão representadas as isóbatas de $10 \mathrm{em} 10 \mathrm{~m}$, bem como as isóbatas de referência $(-10$ e $-130 \mathrm{~m})$, que são limites da área de estudo. Desconsiderou-se a faixa da costa até a isóbata $-10 \mathrm{~m}$ pois esta faixa está sujeita à influência demasiada de fenômenos vinculados às circulações litorâneas e às acumulações sedimentares pertinentes. Optou-se pela isóbata limite $-130 \mathrm{~m}$ por ser a última com comportamento mais regular com as anteriores, situando-se próxima do limite entre a plataforma continental e o início do talude, com forte inclinação a partir da mesma.

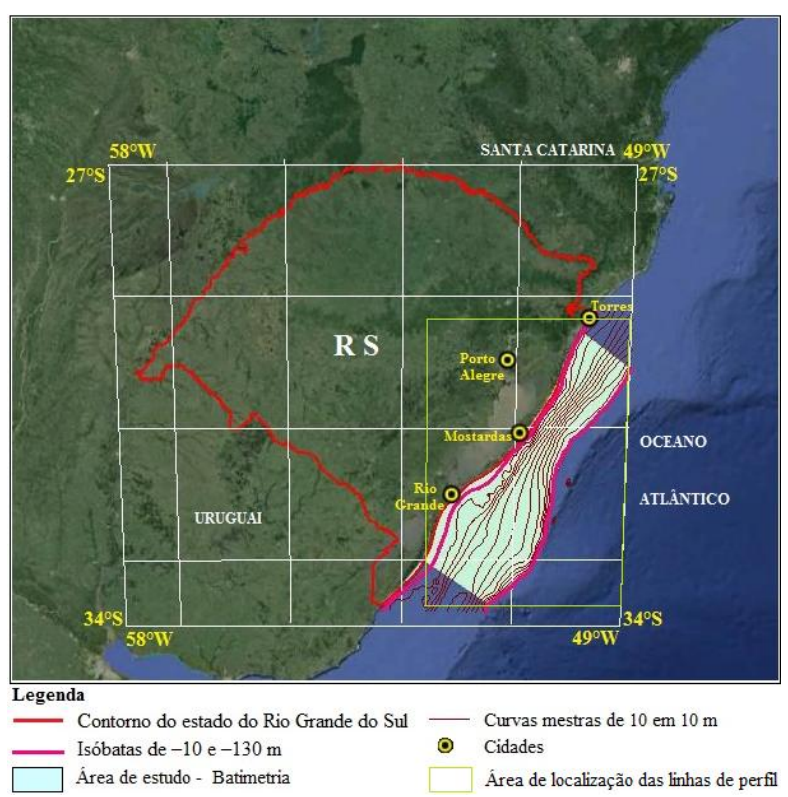

Figura 1 - Localização da área de estudo

A estruturação da bacia sedimentar de Pelotas apresenta forte relação com os eventos tectônicos desencadeados durante a ruptura do supercontinente Gondwana no Cretáceo, ao longo do processo de formação do oceano Atlântico Sul.

\section{Metodologia}

A superfície do oceano apresenta saliências e mergulhos que refletem a topografia do fundo oceânico. A atração gravitacional causada por montes submarinos produz pequenas variações na gravidade, que provocam pequenas alterações de altura da superfície oceânica. Um altímetro de radar de precisão a bordo de um satélite mede as variações de altura da superfície do oceano induzidas pela topografia do assoalho oceânico. As inclinações existentes são reflexo das alterações no campo da gravidade (anomalias da gravidade) da Terra (SANDWELL, D.T. et al, 2002). Assim, a altimetria por satélites fornece informações fundamentais sobre a batimetria a partir 
das alterações medidas da gravidade. Estas informações forma usadas na elaboração de modelos batimétricos, entre eles o DTU10BAT. A série DTU10 focou no melhoramento do campo da gravidade em regiões de águas rasas e regiões polares (ANDERSEN, 2010).

A partir do modelo batimétrico global DTU10BAT, que possui resolução de 1', foram extraídas as informações necessárias para a geração do modelo batimétrico real da área de estudo. Este modelo é um dos produtos globais disponibilizados gratuitamente pelo National Space Institute (DTU Space) na Dinamarca, oriundo da fusão do Danish National Space Center (DNSC) e o Technical University of Denmark (DTU). O Global Bathymetry Model (DTU10-BAT) consiste de um modelo atual, que emprega dados das missões de altimetria por satélites mais recentes, inclusive JASON2 , além de Topex-Poseidon, GEOSAT, etc. Dispondose do grid de pontos para a área de estudo e recursos de softwares específicos, procedeu-se a interpolação pelo método de krigagem. O modelo batimétrico real gerado é apresentado na figura 2, na porção à esquerda, com equidistância entre as curvas de $2 \mathrm{~m}$.

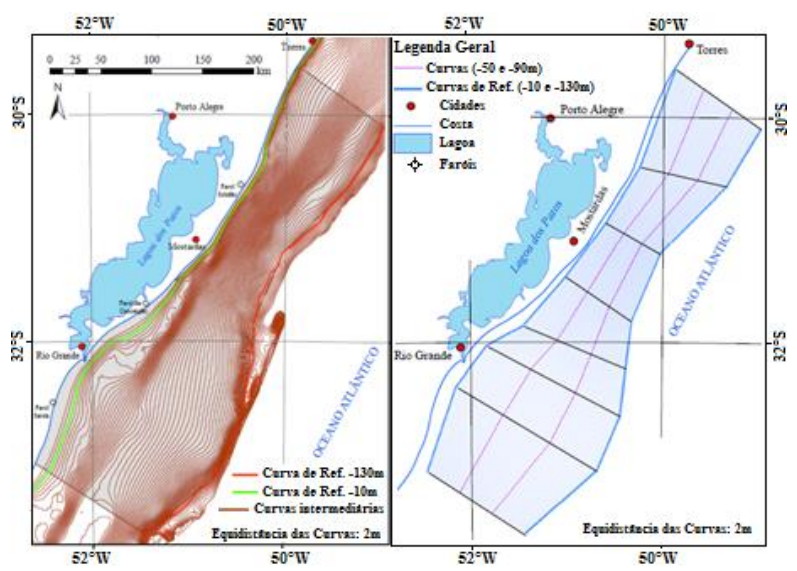

Figura 2 - Modelo batimétrico real (à esquerda) e modelo batimétrico regional teórico (à direita) da área de estudo

Uma das principais técnicas usadas na análise de relevos ou de superfícies consiste na elaboração de superfícies teóricas (CORREA,1990).

\section{Elaboração da Superfície Regional Teórica}

Uma superfície teórica consiste de uma superfície simples, modelada por uma atividade erosiva que exerce a sua ação conforme a linha de maior inclinação, sobre um material homogêneo e isótropo (iguais propriedades em todas as direções). Esta superfície traduz um fenômeno de erosão regional, sendo posteriormente comparada com a superfície real, o que possibilita evidenciar as diferenças, heterogeneidades e anisotropias (propriedades físicas variáveis com a direção) do material que pode ter como origem causas litológicas, tectônicas ou ser oriundo de resíduos de processos erosionais (gliptogênese).

A superfície regional teórica foi construída a partir da suavização das isóbatas $-10 \mathrm{~m}$ e $-130 \mathrm{~m}$, escolhidas como referência, entre as quais foram traçadas as intermediárias. Cada isóbata de referência "teórica" consiste da suavização por partes da curva real, substituída por segmentos retos de extensão variável e que resultam uma linha contínua. São definidas seções distintas pela união dos pontos de inflexão opostos para cada uma destas isóbatas. Considerando-se que entre as isóbatas de referência haja inclinações uniformes, foram interpoladas as isóbatas intermediárias com equidistância de $2 \mathrm{~m}(-12,-14, \ldots$, . $128 \mathrm{~m}$ ) entre as mesmas, ficando definida a superfície regional teórica apresentada na figura 2, à direita.

\section{Anomalias batimétricas regionais}

Convencionou-se denominar de "anomalia batimétrica" a diferença obtida entre a informação batimétrica real (original) oriunda do modelo DTU10BAT, e a informação batimétrica do modelo teórico gerado. Procedendo-se a superposição do modelo real com o modelo regional teórica (figura 2), ocorre a interseção das isóbatas dos dois modelos, definindo as zonas de anomalias regionais. Estas podem ser de dois tipos: anomalias positivas e anomalias negativas, conforme o sentido da diferença entre as curvas da superfície teórica e real para cada ponto. Com estes valores é possível o traçado de curvas de igual diferença (isolinhas) que caracterizam as anomalias batimétricas, que podem estar vinculados a processos tectônicos, fenômenos de erosão/acumulação ou com a litologia.

Foram identificados mais de 2.700 pontos de anomalias batimétricas. Caso se tenha profundidade teórica maior que a profundidade original configura-se uma anomalia positiva. Caso contrário, trata-se de uma anomalia negativa.

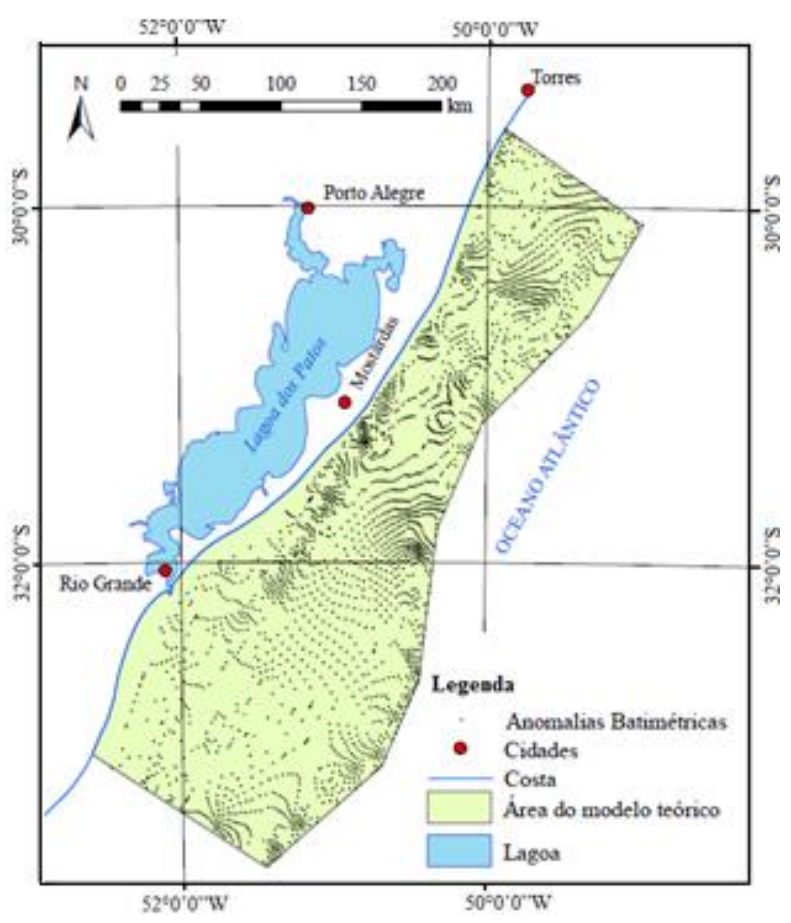

Figura 3-Distribuição das anomalias batimétricas

Conforme Mitas \& Mitasova (1999), o método de interpolação linear do vizinho natural é usado tipicamente para dados de tipos de solo, topográficos, batimétricos e geofísicos, sendo empregado na geração das classes de anomalia batimétrica.

\section{Delineamento das classes e eixos de anomalias} batimétricas regionais 
Os intervalos empregados na geração das classes de anomalias batimétricas foram -20 a $-10 \mathrm{~m}$, de -10 a $-6 \mathrm{~m}$, -6 a $-2 m$, de -2 a $+2 m$, de 2 a $6 m$, de 6 a $10 m$ e de 10 a $40 \mathrm{~m}$. O intervalo entre $-2 \mathrm{~m} \mathrm{e}+2 \mathrm{~m}$ foi considerado como anomalia nula. $\mathrm{Na}$ figura 4 podem ser visualizadas as classes de anomalia batimétrica, bem como a indicação dos eixos de anomalias positivos e negativos e também as descontinuidades observadas entre estas anomalias. As descontinuidades são delineadas onde ocorrem anomalias nulas (tom esverdeado da figura 4).

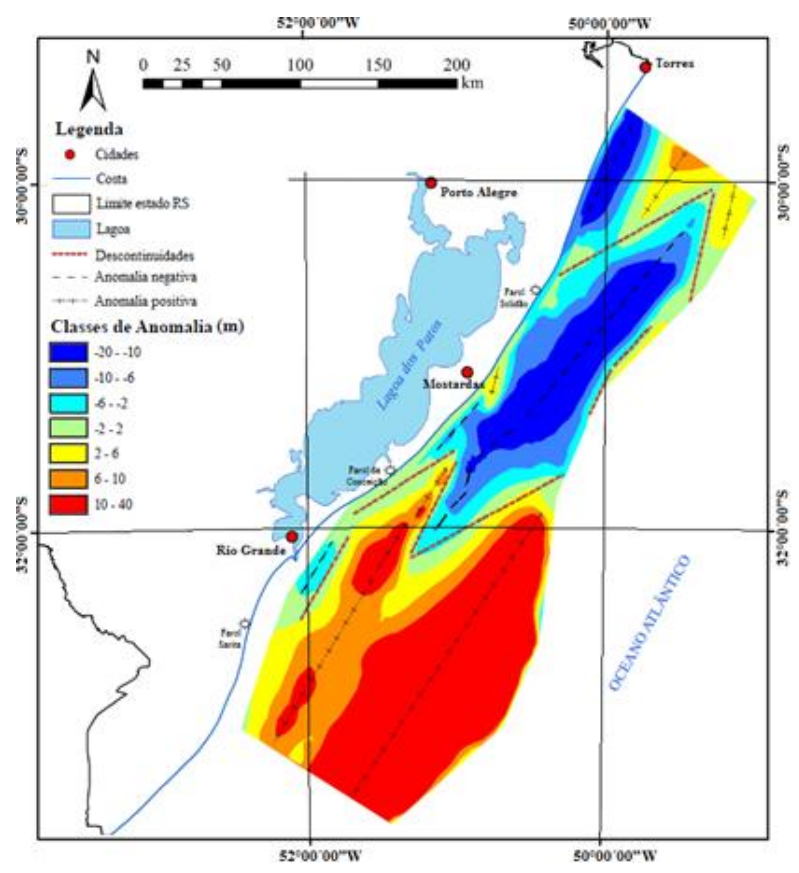

Figura 4-Mapa de classes de anomalias e distribuição dos eixos das anomalias batimétricas

\section{Resultados}

Conforme a figura 4, o comportamento das anomalias batimétricas apresentou as seguintes características:

- Faixa Torres - Farol Solidão: faixa com predomínio de anomalias negativas. Na sua porção mais ao norte identificam-se dois eixos de anomalia positiva, sendo o mais central (anomalia até $10 \mathrm{~m}$ ), situado paralelamente em relação às curvas da superfície regional, e o situado mais afastado do continente com eixo oblíquo às curvas da superfície regional. Há uma região de forte anomalia negativa (até -16 m) próxima à costa, logo abaixo de Torres, apresentando eixo paralelo ao das curvas da superfície regional, e que possivelmente representa uma zona de erosão. Nesta faixa destacam-se descontinuidades posicionadas entre os eixos de anomalias positivas e negativas, sendo uma delas mais acentuada, com direção não paralela à costa, indicativa de continuidade de características morfológicas continentais, e que está ligada à outra descontinuidade que se dirige ao talude. $\mathrm{Na}$ borda da área de estudo, próximo ao talude, há a presença de uma descontinuidade que avança para a faixa subsequente.

- Faixa Farol Solidão - Farol da Conceição: com forte presença de anomalias negativas, nesta faixa ficou evidenciado um eixo bastante longo de anomalia negativa, que se estende por cerca de $150 \mathrm{~km}$ na direção NE-SW, iniciando um pouco ao norte do Farol
Solidão, ainda na zona anterior indo quase até a altura do Farol da Conceição, com anomalias que atingem até $-20 \mathrm{~m}$, principalmente do centro até a sua extremidade norte. Apresenta o eixo paralelo às curvas da superfície regional na sua parte central e oblíquo em suas extremidades. Há a presença de uma descontinuidade na borda desta faixa, próximo ao talude, de comportamento paralelo às curvas da superfície regional.

- Faixa Farol da Conceição - Farol Sarita: predomínio quase total de anomalias positivas, destacando-se nesta faixa duas zonas de anomalias positivas, identificadas por dois eixos de anomalias aproximadamente paralelos, sendo que o situado mais afastado da costa demonstra apresentar continuidade ao sul da área de estudo, com anomalias maiores que $30 \mathrm{~m}$ na extremidade sul e extremo leste (borda), e com valores menores na extremidade norte $(16 \mathrm{~m})$. Há um pequeno eixo de anomalia negativo (até $-6 \mathrm{~m}$ ) ao longo da foz da lagoa dos Patos, que pode ser reflexo do comportamento irregular das isóbatas da região, indicativo de uma morfologia distinta. Há a presença marcante de uma descontinuidade que inicia na altura do paralelo $32^{\circ} \mathrm{S}$, atravessando esta faixa na direção $70^{\circ} \mathrm{NE}$, seguida de outra descontinuidade $20^{\circ} \mathrm{SW}$ e de outra paralela àquela de $70^{\circ} \mathrm{NE}$. Os eixos próximos à costa apresentam anomalias positivas de até $18 \mathrm{~m}$, situada na altura do paralelo $30^{\circ} \mathrm{S}$ e valores que atingem até $12 \mathrm{~m}$ no eixo mais ao sul. Entre estes dois eixos, as anomalias situam-se entre 6 e $10 \mathrm{~m}$.

Constata-se na figura 4 que as anomalias negativas estão concentradas nas faixas norte e central, sendo mais acentuadas nesta última. Na faixa norte, próximo ao continente, tem-se anomalias que alcançam $-16 \mathrm{~m}$ e um eixo situado paralelo às isóbatas de $-28 \mathrm{a}-34 \mathrm{~m}$. Quando se compara com as isóbatas da região (figura 2 ), tal eixo parece estar situado na fronteira entre os valores de inclinações médias e fracas, conforme figura 5. Desta forma, este eixo provavelmente tem uma correlação com a direção de uma paleodrenagem local. Outro eixo de anomalia negativa ocupa praticamente o centro da faixa de estudo, não apresentando direção única. Na sua porção mais ao norte, acima do Farol Solidão, ocorre a mesma situação constatada para o eixo analisado anteriormente, ou seja, este eixo situase em uma zona onde a inclinação passa de média à fraca, representando provavelmente uma linha de paleodrenagem.

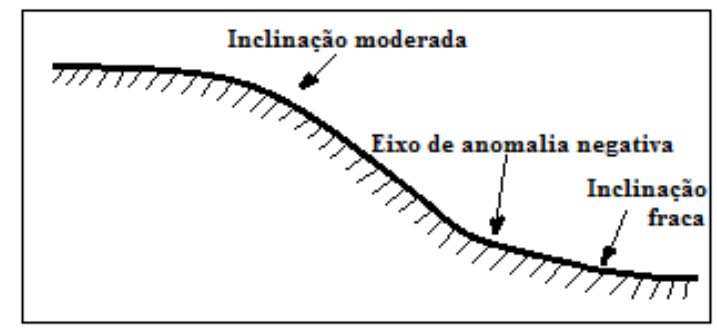

Figura 5 - Posição de eixo de anomalia batimétrica negativa (Adaptado de Corrêa, 1990).

O último eixo citado anteriormente situa-se aproximadamente na altura da isóbata $-100 \mathrm{~m}$. Na sua continuidade para o sul, o eixo situa-se em grande parte coincidente com a isóbata $-96 \mathrm{~m}$, até a altura de Mostardas. Na sequencia apresenta-se numa direção oblíqua às curvas batimétricas até voltar a ter 
comportamento paralelo, agora coincidente com a isóbata $-58 \mathrm{~m}$, fato que se mantém na sua extensão final, já na faixa que se inicia no Farol da Conceição, região na qual se verifica novamente o que está representado na figura 5 .

Na faixa entre o Farol Solidão até o Farol da Conceição foi constatada uma anomalia negativa expressiva, que corresponde à chamada área do Baixo de Mostardas, uma depressão estrutural com orientação NW-SE.

Referente às anomalias positivas, as mesmas são mais acentuadas na zona sul deste estudo, ocorrendo com menor intensidade na zona norte. Nesta última, o eixo mais importante identificado situa-se paralelo às isóbatas -54 e $-56 \mathrm{~m}$, numa situação de fronteira de inclinação fraca para média e alta, o que demonstra que este eixo pode estar ligado às linhas de paleodrenagens, tal como constatado por Corrêa (1990). Na faixa do Farol da Conceição até o Farol Sarita e pouco abaixo, há dois eixos de anomalias positivas, sendo um deles próximo da costa, segmentado em duas partes, acompanhando a isóbata $-22 \mathrm{~m}$ na parte superior. A segunda parte é mais longa, sendo que o eixo situa-se paralelo às isóbatas $-22 \mathrm{~m}$ e -24 m nas partes superior e inferior do mesmo, sendo oblíquo às demais isóbatas na parte central. Este eixo está localizado em uma zona de declive suave, fazendo fronteira com uma zona de declive mais acentuado, como demonstrado na figura 6 . Este eixo também pode ser correlacionado com um alto estrutural (horst).

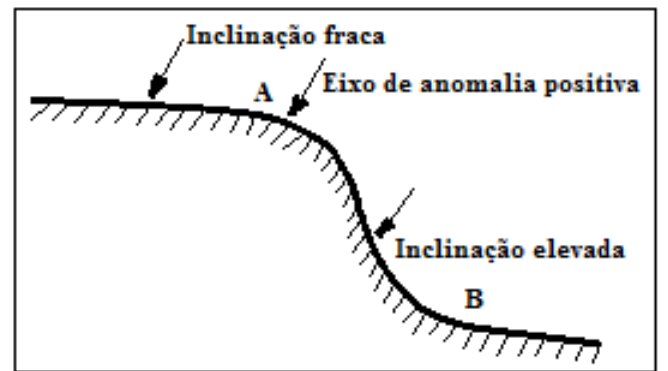

Figura 6-Posição de eixo de anomalia batimétrica positiva (Adaptado de Corrêa, 1990).

O segundo eixo está mais afastado do continente, tendo quase $200 \mathrm{~km}$ de extensão, com disposição oblíqua na faixa entre as isóbatas $-66 \mathrm{~m}$ e $-104 \mathrm{~m}$ na sua parte superior, e comportamento quase paralelo à isóbata $-66 \mathrm{~m}$ na parte inferior.

Pode-se afirmar que de maneira geral, a ocorrência de anomalias residuais, seja positiva ou negativa, sugere a presença de um evento morfológico expressivo que tenha perturbado o arranjo geral da região, como por exemplo, reflexo da deriva dos continentes.

$O$ fato de alguns eixos de anomalias apresentarem obliquidade quando comparados às curvas da superfície regional (ou mesmo do modelo batimétrico real), parece indicar a existência de um controle estrutural para sua implementação (falhas, dobramentos, etc). Desta forma, torna-se evidente que as anomalias relacionadas com a ação do mar somente poderiam apresentar direções paralelas aos estágios de estacionamento destas direções ou da atuação de agentes hidrodinâmicos.
Do ponto de vista de uma interpretação geológica das anomalias observadas, pode-se afirmar que as anomalias positivas estão situadas na direção de fortes acumulações sedimentares, ao passo que as anomalias negativas geralmente correspondem às baixas acumulações ou áreas em que houve remobilização sedimentar. Assim, considerando-se a dinâmica do mar, pode-se afirmar que na região "A" da figura 8.25 há acúmulo de sedimentação mais fina, com formação de terraços, ao passo que na região "B" há o acúmulo de sedimento mais grosso.

\section{Discussão e Conclusões}

Sob o aspecto de análise do relevo, pode-se afirmar que os fundos submarinhos da plataforma continental do RS não apresentam grandes complexidades nos seus contornos originais, o que permite seu estudo através da análise de superfícies regionais teóricas. $O$ uso de dados de altimetria por satélites, tão facilmente acessíveis à comunidade usuária, conduziu a resultados que permitiram a caracterização morfoestrutural da plataforma continental do Rio Grande do Sul. As anomalias batimétricas verificadas indicam a ocorrência de um evento morfológico significativo que interferiu no arranjo estrutural da região, possivelmente como reflexo da deriva dos continentes.

\section{Agradecimentos}

Os autores agradecem ao Instituto de Geociências da Universidade Federal do Rio Grande do Sul pela disponibilidade de laboratórios na execução deste trabalho.

\section{Referências}

ANDERSEN, O.B. 2010. Marine Gravity and Geoid from Satellite Altimety, Chapter 9. Disponível em $\mathrm{ftp}: / / \mathrm{ftp}$. space.dtu.dk/pub/Altimetry/SANSO/OLD VERS ION/Chapter9 v1.0.pdf

CORRÊA, I.C.S., 1990. Analyse morphostructurale et evolution paléogeographique de la plate-forme continentale Atlantique Sud-bresilienne (Rio Grande do Sul - Brésil). Doctoral These - Univ. Bordeaux I. Talence, France, 314p.

FONSECA, V. P., 2006. Estudos morfotectônicos aplicados à Planície Costeira do Rio Grande do Sul e adjacências. Tese de Doutorado em GeociênciasInstituto de Geociências. Universidade Federal do Rio Grande do Sul. Porto Alegre, 306p.

MITAS, L.; MITASOVA, H., 1999, Spatial Interpolation. In: LONGLEY,P. GOODCHILD, M.F.; MAGUIRE, D.J.; RHIN, D.W. (Ed.). Geographical Information Systems: principles, techniques, management and applications. New York: John Wiley, Cap. 34, p. 481 $492 . \quad$ Disponível em: $<$ http://civil.colorado.edu/ verdina/BlendingPapers/Blen ding\%20Paper\%201/references/mitas_mitasova_1999_ 2005.pdf>. Acesso em: 05 jun 2013.

SANDWELL, D.T.; GILLE, S.T.; SMITH, W.H.F. (Ed.). 2002, Bathymetry from Space: oceanography, geophysics, and climate. Bethesda, Maryland, 
Geoscience Professional Services. 24 p. Disponível em: <http://www.igpp.ucsd.edu/bathymetry_workshop>. 